\title{
AC 2010-673: MOTIVATING STUDENTS TO LEARN MORE: A CASE STUDY IN ARCHITECTURAL EDUCATION
}

\section{Joseph Betz, State University of New York}

Joseph A. Betz is an architect and Professor in the Department of Architecture \& Construction Management at the State University of New York College of Technology at Farmingdale. He received his undergraduate and professional degrees in architecture from the Rensselaer Polytechnic Institute and his post-professional degree in architecture from Columbia University. A recipient of the SUNY Chancellor's Award for Excellence in Teaching, he has served as both national Program Chair and Division Chair of the Architectural Engineering Division of the American Society for Engineering Education. 


\title{
Motivating Students to Learn More: a case study in Architectural Education
}

\begin{abstract}
Motivational techniques have been successfully used in the workplace to increase worker productivity for many decades. These same techniques can also be used in the classroom to increase learning. This study applies a workplace motivational technique called the Expectancy Theory of Motivation by Victor Vroom to a group of undergraduate architectural engineering technology students. It measures the relative difference in learning between two groups of students: one, an experimental group where the motivational technique is applied, and the other, a control group where it is not. The experiment uses a standard set of readings that are given to both groups of students followed by a multiple choice test. Faculty teaching of the material was not a factor in the experiment, only the motivational technique used by the faculty in the experimental group was. Both study groups are benchmarked prior to performing the experiment. Two different methods of analysis are used: one, descriptive statistics and two, a non-parametric rank sum probability test to show chance was not a factor in this small sample size. A survey was used to collect student attitudes and perceptions on motivating factors. The implication of these findings will be to provide faculty with motivational tools to increase student learning.
\end{abstract}

\section{Introduction}

If we could only motivate our students, maybe they would learn more and perform better. This is a common theme expressed by faculty. We feel this way because we are partly responsible for creating successful learning environments. Motivation plays an important part in our performance and it must be so with students also. A question we may ask ourselves is, "Can we incorporate motivational techniques in our teaching to increase student performance?" If so, how much of a factor is it? What aspects of these motivational techniques work the best and seem to make a difference to students?

We like to think that architectural and engineering students differ from general studies or liberal arts majors in that they have a more narrow focus for their career goals and associated learning objectives. When we were students, we typically focused more on courses in the major because we knew that it would someday lead to a job, and so on. Assuming our instructors created a warm and inviting learning environment, how much more could they have done to motivate us in the discipline?

This paper takes Victory Vroom's Expectancy Theory ${ }^{1}$ on motivation and applies it to a group of undergraduate architectural engineering technology (AET) students to see what factors motivate them to learn more and perform better today. This paper is not meant to be an in-depth scientific study in student motivation or behavioral psychology and gives only a cursory outline of Vroom's Expectancy Theory. This paper is testing if it is possible for faculty to motivate students in architectural engineering programs beyond a student's internal self motivation to learn more or perform better using the theory as a conceptual framework. Can an instructor take ten or fifteen minutes out of class time and try to motivate students to increase performance? Does it have an influence on student attitudes? Is it worth valuable classroom time to incorporate motivational techniques at all and what works? 
This paper measures the relative difference in learning using two groups of students: one, an experimental group where the motivational technique is applied, and the other, a control group where it is not. The experiment used a standard set of readings that are given to both groups of students followed by a multiple choice test. Faculty teaching of the material was not a variable in the experiment, only the motivational technique used by the faculty in the experimental group was. Both study groups are benchmarked prior to performing the experiment. Two different methods of data analysis are used: one, descriptive statistics and two, a non-parametric rank sum probability test to show chance was not a factor in this small sample size. A survey was used to collect student attitudes and perceptions on motivating factors. A conclusion is given in the discussion area along with data and survey results.

\section{Basic Concepts - Expectancy Theory}

This paper will focus on the Expectancy Theory as developed by Victor Vroom in his influential publication, Work and Motivation. ${ }^{2}$ Tailoring his theory to an educational environment, it suggests that the amount of motivation and effort a student will put into learning will depend on three perceptual relationships: (1) expectancy, a student's estimation of the likelihood of successfully performing the particular assignment. Faculty should have an understanding what information and resources students will need to be successful; (2) instrumentality, a student's estimation of the likelihood that the effort they put in will be in positive results. Faculty should make sure all efforts are rewarded; and (3) valence, the value the student places on each of the outcomes; what are the rewards and will they satisfy a need? Faculty should find out what those specific needs and rewards are. All three of these factors need to be present to influence motivation. It requires that faculty have an in-depth understanding of students in all three areas or survey them in advance to define them. If a student is to be highly motivated, all three factors of the expectancy model must be high. If even one of these factors is zero (e.g., instrumentality and valence are high, but expectancy is completely absent), the student will have no motivation for the task. Thus, the faculty should attempt to ensure that their students believe that increased effort will improve performance and that performance will lead to valued rewards. Because Vroom's Expectancy Theory falls into a broad category of behavioral process theories it requires students to assess the extent to which they perceive that their performance is instrumental in obtaining rewards and that they can achieve those results. A student survey questionnaire will collect these attitudes and perceptions.

This theory suggests that an individual's expectations about their ability to accomplish something will affect their success in doing so. Therefore, this theory is based on cognition and thought processes. It is part of a broad set of cognitive process theories on motivation. Process theory focuses on conscious human decision making as an explanation of motivation. The theory looks at how individuals choose particular behaviors and how they determine if these behaviors can meet their needs. It also is concerned with performance and outcome. Major process theories of motivation other than the Expectancy Theory are: Equity Theory, Goalsetting Theory, and Reinforcement Theory. The Expectancy Theory was selected herein because it is cognitively based and fits well in an educational environment that uses the same cognitive strategies for higher learning. 


\section{Brief Theoretical Background / Literature Search}

The Expectancy Theory developed by Victor Vroom has held the major place in work and motivation theory since 1964. Vroom's associations of expectancy-valence- instrumentality is one of the most researched theories in the field being cited in more than 1,430 scholarly publications between 1966 and 1985. ${ }^{3}$ A Google Internet search using the terms, "Victor Vroom Expectancy Theory of Motivation," yields more than 87,400 hits as of January 2010; nearly forty five years after publication. The work has implications in many areas of including: organizational behavior, ${ }^{4}$ training motivation, ${ }^{5}$ goal setting, ${ }^{6,7,8,9,10,11,12}$ and leadership. ${ }^{13}$ Recent educational applications include college student performance and retention, ${ }^{14}$ grade motivation, ${ }^{15}$ and teacher applications. ${ }^{16}$ The methodologies tested in empirical research have varied in many ways. ${ }^{17,18,} 19,20,21,22$ Van Eerde \& Thierry ${ }^{23}$ suggest that the models and components used by researchers are abstract and susceptible to different interpretations in terms of what the measurements mean and how data was collected. Based on a variety of methodologies and interpretations of data, it is assumed that there is a degree of robustness, flexibility and application that can be allowed in this study since there is no one agreed upon right way to conduct this experiment.

\section{Application and Assumptions}

The application of the Expectancy Theory in this study will be both practical and conceptual. It is meant to be used in the classroom as a teaching tool, in the context of the art and craft of teaching to increase student learning and productivity, and not a scientific test of the theory itself. One major departure from the theory will be to assume what the motivational rewards are for students, in broad terms, rather than trying to explore those needs individually as suggested by Vroom. ${ }^{24}$ These assumptions for student rewards are a combination of the following: short term recognition of success as indicated by grades; long term achievement leading to career goals and financial success; peer status; parental and faculty acknowledgement and praise; ego, self expectations and identity, etc. The reward a faculty member can generally offer students are grades, praise and status. Other rewards are usually taken for granted but this study will also use explicit connections to long term goals and learning objectives: professional licensure, leadership (principal/partner in a firm), financial success, etc.

\section{Method}

Subjects

This study was conducted in the fall semester of 2009 in an Architectural Design I course. There were two groups of students a Control Group and an Experimental Group. The Control Group is defined as a group students who where given a reading assignment followed by an examination. The Experimental Group is defined as a group students who where given a motivational talk, followed by a reading assignment and then an examination. The students were sophomores and the group size for each was $\mathrm{N}=12$; twenty four students participated in total.

\section{General Procedures}

Both the control group and experimental group were given two short readings ${ }^{25}$ from the PreDesign 2 Section of the Architectural License Seminars (ALS) study guides for the Architectural Record Exam (ARE), copyright $1985 .{ }^{26}$ Reading 1 was Form Prototypes and Reading 2 was Scheduling of Design and Construction Outline. After both readings, students were given a multiple choice examination developed by ALS based on the reading; the instructor did not 
develop the material or multiple choice examinations used in this study. The only difference between the two readings was Reading 1 was used to baseline the performance of both groups and Reading 2 applied the motivational technique as the independent variable to the Experimental Group.

Benchmarking both groups was necessary because there is the possibility that learning or test taking differences exist between the Control Group and the Experimental Group. This study will measure the relative difference (delta) between the average test scores of Reading 1 and Reading 2 and not compare the absolute test scores between the groups.

Both groups were told on Reading 1 that due to time restrictions, a reading on a topic from the pre-design section of the ARE exam was given out to supplement their learning. It would be followed by a short exam after. Students were told that this would be something they would someday have to know in the future for ARE exam. No other additional information was given out regarding the examination, why they were doing this or how it would count grade wise.

Reading 2 was the second reading given to both the Control Group and the Experimental Group. The Control Group was told that this is the same learning activity as Reading 1. The Experimental Group was given a fifteen minute motivational talk by the instructor prior to doing Reading 2 and taking the examination. The motivational techniques used were based on Vroom's three factors: expectancy, instrumentality and valence as outlined below.

\section{Motivational techniques described}

There were three areas of motivation discussed with the Experimental Group over a fifteen minute period: expectancy, instrumentality and valence. Students were told that the Reading was well developed, to the point and time tested. It was designed so students who read the material would score well on the examinations. Students were also told that they had all the skills and background education to do very well on the exam. All they really had to do was study the material, take it seriously and they would do well. This covered the area of expectancy.

Students were told that their test scores would be graded holistically and that I would curve the results. This is what I have always done on all of my examinations in the past and that this was beneficial to the students' success on tests and mitigates any unfairness in the examination questions. This was done to make sure their hard work was properly rewarded. In addition, any students scoring an A or B on the exam would have an earlier one-day design problem grade increased one letter grade as very modest recognition for doing well.

Students were also told that the material was important to learn if they wanted to pass the ARE exam and become licensed architects; the end result of all their efforts for possibly the next eight to ten years. As an added comment, they were told that they were one of the best classes I have had and that I know they would not let me down and that I had full confidence in them; an additional emotional incentive. This covered the areas of instrumentality and valence.

The students seemed engaged with the rational I gave them for learning this material but the only questions that were brought up were those regarding the assessment and how much it would really count toward the course grade. As a faculty member, this is not what I would consider the 
most important aspect of motivating students to learn but to them it seemed like an extra credit reward scheme; it couldn't hurt and could possibly add to their grade if it was on the borderline.

\section{Survey Questions}

After completing Reading 2 but prior to taking the Examination 2, both groups of students were given ten survey questions to answer. In addition to measuring the difference between the two examination scores, both groups needed to be surveyed regarding the motivational aspects of expectancy, instrumentality and valence. The goal was to find out what motivational factors seemed to make a difference for students.

\section{Results}

\section{Descriptive Findings}

The results from the Examination Scores and Difference (Delta) are shown in Table 1. Use of the motivational techniques yielded an increase in difference (Delta) $=0.57$ or slightly more than half a relative letter grade increase for the Experimental Group over the Control Group's performance.

Table 1 Examination Scores and Difference (Delta)

\begin{tabular}{|l|l|l|l|}
\hline Group & $\begin{array}{l}\text { Exam Score 1 from Reading 1 } \\
\text { baseline exam for both groups }\end{array}$ & $\begin{array}{l}\text { Exam Score 2 from Reading 2 } \\
\text { variable applied (motivation) }\end{array}$ & $\begin{array}{l}\text { Difference between } \\
\text { Exam Score 1 and 2 }\end{array}$ \\
\hline Control Group & Group average $=5.75$ & Group average $=6.58$ & Delta $=0.83$ \\
\hline Experimental Group & Group average $=6.27$ & Group average $=7.67$ & Delta $=1.40$ \\
\hline Total Difference & & & Delta $=0.57$ \\
\hline
\end{tabular}

The results from the Survey Questions are shown in Table 2. Nine of the ten survey questions resulted in a positive motivational difference in favor of the Experimental Group. The two most significant questions that generated the highest difference were No. 4, "Did the instructor provide an understanding as why you are learning this information?" and, No. 10, "Do you have confidence in the professor's fairness in grading?" The only survey question to result in negative difference was No. 2, "How confident are you that you will do well?" Maybe students felt pressured to perform better from the motivational discussion.

Table 2 Survey Questions

\begin{tabular}{|c|c|c|c|}
\hline Survey Questions - on a scale from 1(lowest) to 10 (highest) & $\begin{array}{l}\text { Control } \\
\text { Group }\end{array}$ & $\begin{array}{l}\text { Experimental } \\
\text { Group }\end{array}$ & Difference \\
\hline 1. Do you think the information is valuable to you? & 8.75 & 9.25 & $0.50+$ \\
\hline 2. How confident are you that you will do well? & 7.66 & 7.08 & $0.58-$ \\
\hline 3. Do you think the handout was well written? & 8.08 & 8.17 & $0.08+$ \\
\hline $\begin{array}{l}\text { 4. Did the instructor provide an understanding as why you are } \\
\text { learning this information? }\end{array}$ & 7.00 & 9.08 & $2.08+$ \\
\hline 5. Did you feel confident about learning this new information? & 7.83 & 7.92 & $0.09+$ \\
\hline 6. Do you believe you have the background to do well? & 7.42 & 7.50 & $0.08+$ \\
\hline 7. Do you believe you will be successful in learning this information? & 8.17 & 8.25 & $0.08+$ \\
\hline 8. Do you believe you will be successful on the exam? & 6.92 & 7.5 & $0.58+$ \\
\hline 9. Do you understand the rewards for doing well? & 9.33 & 9.58 & $0.25+$ \\
\hline 10. Do you have confidence in the professor's fairness in grading? & 8.42 & 9.42 & $1.00+$ \\
\hline
\end{tabular}




\section{Non-parametric Rank Sum Probability Analysis}

The paper will use the Mann-Whitney-Wilcoxon rank-sum test, (herein called the MannWhitney $U$ test) for assessing whether the two samples are drawn from a single distribution and therefore that their probability distributions are equal. ${ }^{27}$

The Mann Whitney $\mathrm{U}$ statistic is defined as:

$$
U=n_{1} n_{2}+\frac{n_{2}\left(n_{2}+1\right)}{2}-\sum_{i=n n_{2}+1}^{n 2} R_{i}
$$

Where samples of size $n_{1}$ and $n_{2}$ are pooled and $R_{i}$ are the ranks. $U$ is the number of times observations in one sample precede observations in the other sample in the ranking. The $P$ value or calculated probability is the estimated probability of rejecting the null hypothesis $(\mathrm{Ho})$ of the two samples when that hypothesis is true, "no difference." The choice of significance level at which you reject $\mathrm{Ho}$ is arbitrarily set at 5\% (less than 1 in 20 chance of being wrong). The two samples are not significantly different when $\mathrm{P}>=0.05$ for the two-tailed test. The $U$ and $P$ values are shown below in Table 3.

\section{Table 3: Mann-Whitney $U$ test calculations ${ }^{28}$}

\begin{tabular}{|l|l|l|l|l|}
\hline$n_{1}$ & $n_{2}$ & $U$ & $P$ (two-tailed) & $P$ (one-tailed) \\
\hline 12 & 12 & 93.5 & 0.21892 & 0.10946 \\
\hline \multicolumn{2}{|l}{ normal approx. $\mathrm{z}=1.2413$} & $0.214494^{*}$ & $0.107247^{*}$ \\
\hline
\end{tabular}

*These values are approximate.

The two samples are not significantly different ( $\mathrm{P}>=0.05$, two-tailed test).

Chance is not a significant factor in the data results where motivation was applied as a variable.

\section{Discussion}

The results obtained herein have noteworthy implications for how faculty can motivate students and the results that can be expected. The motivational techniques used herein were the only variable that separated the Control Group from the Experimental group. From this we can narrow the explanation of the phenomena that has occurred. Here are the findings: fifteen minutes of motivational discussion with students prior to starting a one hour learning assignment yielded a half of a letter grade on learning performance. Based on the student attitude survey, the biggest motivating factor was providing an understanding for students as to why they are learning the information. The next biggest factor was explaining the assessment. Many of the other factors that Vroom outlines in his Expectancy Theory did not seem to make a significant difference or were not perceived by students to do so. It is generally understood by faculty that it is important to tell students why they are learning something and how they will be assessed. Beyond that, students come to college motivated to learn for many reasons, some of which only makes sense to them. Faculty cannot spend time finding out what those motivating factors as Vroom suggests, in the context of a complex taxonomy of learning goals. The conclusion here is that the Vroom's Expectancy Theory is too complex and not a good motivational model for students in an architectural engineering technology programs, they are motivated already. Only parts of his motivational theory seemed to have an affect on students. As teaching practitioners, a commonsense explanation to students of why they are learning something and how it will be assessed is really the key to motivation and better performance. The study does warrant further investigation due to the small sample size and should be replicated accordingly. 


\section{References}

${ }^{1}$ Vroom, V. H. (1964). Work and motivation. New York: Wiley.

${ }^{2}$ Vroom, V. H. (1964). Work and motivation. New York: Wiley.

${ }^{3}$ Social Science Citation Index (SSCI), July 8, 1985.

${ }^{4}$ Naylor, J. C., Pritchard, R. D., \& Ilgen, D. R. (1980). A theory of behavior in organizations. New York: Academic Press.

${ }^{5}$ Mathieu, J. E., Tannenbaum, S. I., \& Salas, E. (1992). "Influences of individual and situational characteristics on measures of training effectiveness." Academy of Management Journal, 35, 828-847.

${ }^{6}$ Dachler, H. P., \& Mobley, W. H. (1973). "Construct validation of an instrumentality-expectancy-task-goal model of work motivation: Some theoretical boundary conditions." Journal of Applied Psychology, 58, 397-418.

${ }^{7}$ Earley, P. C., \& Lituchy, T. R. (1991). "Delineating goal and efficacy effects: A test of three models." Journal of Applied Psychology, 76, 81-98.

${ }^{8}$ Garland, H. (1985). "A cognitive mediation theory of task goals and human performance." Motivation and Emotion, 9, 345-367.

${ }^{9}$ Klein, H. J. (1991). "Further evidence on the relationship between goal setting and expectancy theory." Organizational Behavior and Human Decision Processes, 49, 230-257.

${ }^{10}$ Locke, E. A., Frederick, E., Lee, C., \& Bobko, P. (1984). "Effects of self-efficacy, goals and task strategies on task performance." Journal of Applied Psychology, 69, 241-251.

${ }^{11}$ Meyer, J. P., \& Gellatly, I. R. (1988). "Perceived performance norm as a mediator in the effect of assigned goal on personal goal and task performance." Journal of Applied Psychology, 73, 410-420.

${ }^{12}$ Reidel, J. A., Nebeker, D. M., \& Cooper, B. L. (1988). "The influence of monetary incentive on goal choice, goal commitment, and task performance." Organizational Behavior and Human Decision Processes, 42, 155-180.

${ }^{13}$ House, R. J. (1971). “A path goal theory of leader effectiveness.” Administrative Science Quarterly, 16, 321328.

${ }^{14}$ Friedman, B. A. and Mandel, R. G. (2009-10). "The Prediction of College Student Academic Performance and Retention: Application of Expectancy and Goal Setting Theories.” Journal of College Student Retention: Research, Theory \& Practice v11 n2 p227-246.

${ }^{15}$ Johnson, M. (2007). "Does the Anticipation of a Merit Grade Motivate Vocational Test-Takers?" Research in Post-Compulsory Education v12 n2 p159-179.

${ }^{16}$ Hancock, D. R. (1995). "What Teachers May Do to Influence Student Motivation: An Application of Expectancy Theory." Journal of General Education v44 n3 p171-79.

${ }^{17}$ Campbell, J. P., \& Pritchard, R. D. (1976). Motivation theory in industrial and organizational psychology. In M. D.Dunnette (Ed.), Handbook of industrial and organizational psychology (pp. 63-130). Chicago: Rand McNally.

${ }^{18}$ Klein, H. J. (1991). "Further evidence on the relationship between goal setting and expectancy theory." Organizational Behavior and Human Decision Processes, 49, 230-257.

${ }^{19}$ Mitchell, T. R. (1974). "Expectancy models of job satisfaction, occupational preference and effort: A theoretical, methodological, and empirical appraisal." Psychological Bulletin, 81, 1053-1077.

${ }^{20}$ Nickerson, C. A., \& McClelland, G. H. (1989). "Across-persons versus within-persons tests of expectancy valence models: A methodological note." Journal of Behavioral Decision Making, 2, 261-270.

${ }^{21}$ Wanous, J. P., Keon, T. L., \& Latack, J. C. (1983). "Expectancy theory and occupational/organizational choices: A review and test." Organizational Behavior and Human Performance, 32, 66-86.

${ }^{22}$ Schwab, D. P., Olian-Gottlieb, J. D., \& Heneman, H. G., III. (1979). "Between-subjects expectancy theory research: A statistical review of studies predicting effort and performance." Psychological Bulletin, 86, 139-147.

${ }^{23}$ Van Eerde, W., Thierry, H. (1996). "Vroom's expectancy models and work-related criteria: A meta-analysis." Journal of Applied Psychology, Vol 81(5), pp. 575-586.

${ }^{24}$ An experienced teacher who connects with their students will usually understand what motivates them.

${ }^{25}$ Each reading was approximately 15 pages in length.

${ }^{26} \mathrm{We}$ are assuming that the readings and corresponding examinations at the end of each reading developed by ASL, and used for several decades, are independent, well written, market tested and unbiased for use in this study.

${ }^{27}$ Conover, W. J. (1980). Practical Nonparametric Statistics, 2nd Edition, Hoboken, NJ: John Wiley \& Sons, pp. $225-226$.

${ }^{28}$ A script was used to do the calculations, URL: http://elegans.swmed.edu/ leon/stats/utest.cgi 